\title{
Encontros e desencontros: uma proposta de práticas pedagógicas para o ensino de Português como L2 para surdos
}

\author{
Vanessa Gomes Teixeira Anachoreta ${ }^{\mathrm{i}}$
}

\begin{abstract}
RESUMO
Ao analisar os raros materiais para o ensino de Português para surdos, observa-se que muitas particularidades do processo de aprendizagem desses alunos não são respeitadas nas propostas de atividades. Levando em conta tal lacuna, o presente trabalho busca elaborar práticas pedagógicas voltadas para o ensino da modalidade escrita do Português como segunda língua para surdos. Para isso, o planejamento do material foi baseado em dois pilares: as necessidades que emergiram de um contexto real de aprendizagem para surdos e a revisão de literatura nas áreas de Aquisição de segunda língua, condição PósMétodo, Português como L2 para surdos, Teoria dos Sistemas Complexos e Planejamento de materiais para o ensino de L2. A partir da pesquisa, foram reunidos pressupostos para as práticas e, por fim, foram elaborados os materiais.
\end{abstract}

Palavras-chave: Aquisição de segunda língua; Português para surdos; Elaboração de materiais.

\begin{abstract}
Through the analysis of existing material for teaching Portuguese to the deaf, we noticed that several particularities of the learning process of the deaf student are not respected in proposed activities. With this gap in mind, we seek to elaborate best pedagogic practices aimed at the written modality of Portuguese as a second language for the deaf. To achieve this goal, we based the preparation of the material on two pillars: the needs that arise in an authentic Portuguese-learning context for deaf students and the literature review in the areas of Second Language Acquisition, Post Method Condition, Portuguese as L2 Condition for deaf people, Complexity Theory and Materials for L2 teaching. Finally, we gathered assumptions for the practices and elaborated the materials were elaborated based on the research.
\end{abstract}

Keywords: Second language acquisition; Portuguese for the Deaf; Material elaboration.

\footnotetext{
${ }^{i}$ Doutora em Ciências da Linguagem na Faculdade de Letras da Universidade de Porto (Portugal). Desenvolve pesquisas na área de Linguística e Língua Portuguesa.

E-mail: vanessa_gomesteixeira@ hotmail.com
} 


\section{INTRODUÇÃO}

A Declaração de Salamanca (1994), de que o Brasil é signatário, defende a chamada Educação Inclusiva, que possibilita a inclusão de todos os alunos no ensino e busca respeitar as necessidades de cada um. Tal proposta busca a construção de uma escola democrática que respeita as diferenças e visa à participação integrada de todos os estudantes nos estabelecimentos de ensino regular, reestruturando a escola para que ela seja voltada para a diversidade dos alunos e suas singularidades.

No caso do Brasil, com a Nova Constituição Brasileira de 1988, começa a se pensar em uma educação para todos, levando em conta as especificidades de cada aluno. No caso da comunidade surda, a Política Nacional de Inclusão - a qual é inspirada na Declaração de Salamanca (1994) - considera que alunos com necessidades especiais devem ser incluídos em escolas regulares e prevê a aprendizagem da Língua Brasileira de Sinais como primeira língua dessa comunidade, e do Português, na modalidade escrita, como segunda língua. Com essa proposta, verificamos a preocupação no campo educacional em adaptar metodologias de ensino e materiais didáticos para que as especificidades dos alunos surdos sejam levadas em conta e, dessa forma, eles possam ser incluídos no cotidiano escolar.

Nesse contexto, surge um novo olhar em relação ao ensino do Português para essa comunidade: se antes era ensinado como língua materna nas escolas regulares ou especiais, começa a se pensar no ensino de Português como segunda língua para alunos surdos. Entretanto, o que se observa na realidade é que ainda são escassos os materiais que preveem o Português como língua não materna para surdos e que levem em conta as especificidades da comunidade surda. Além disso, ao analisarmos materiais existentes, muitas particularidades do processo de aprendizagem do aluno surdo não são respeitadas nas propostas de atividades, como a percepção visual, a LIBRAS, os aspectos culturais da comunidade surda, entre outros. Levando em conta essa lacuna na área, o presente artigo tem como objetivo elaborar práticas pedagógicas voltadas para o ensino da modalidade escrita do Português como segunda língua para surdos.

Para a elaboração das práticas, foram feitos os seguintes questionamentos: (a) Como se organiza um contexto em que surdos e ouvintes aprendem o Português e quais 
suas particularidades?; (b) Quais critérios devem ser utilizados para a elaboração de práticas pedagógicas no ensino de Português como L2 para surdos?

Para responder essas perguntas, o percurso metodológico organizou-se em quatro momentos. Na primeira etapa, foram feitas duas visitas à escola Integração ${ }^{1}$. Já no segundo momento, foi realizada uma pesquisa bibliográfica sobre as seguintes áreas: Aquisição de Segunda Língua; Condição Pós-Método; Teoria dos Sistemas Complexos; Português para surdos, e Materiais para o ensino de L2. A partir da revisão de literatura, foram reunidos pressupostos para a elaboração de práticas pedagógicas. Na terceira etapa, foram pensadas as possibilidades para a elaboração de materiais de PL2 para surdos, tendo como base os pressupostos gerados nas etapas anteriores. Por fim, na quarta etapa, foram elaboradas práticas pedagógicas voltadas para alunos surdos.

\section{A REALIDADE DE UM CONTEXTO INCLUSIVO: VISITAS À ESCOLA INTEGRAÇÃO}

Para responder a pergunta (a) Como se organiza um contexto em que surdos e ouvintes aprendem o Português e quais suas particularidades?, foram realizadas duas visitas à escola Integração. Na primeira visita, a coordenadora pedagógica explicou como funcionava o colégio: segundo suas informações, a escola Integração ${ }^{2}$ atende surdos e ouvintes e abrange da Educação Infantil ao $9^{\circ}$ ano do Ensino Fundamental. A respeito da questão linguística, a instituição trabalha com a oralização, o ensino de LIBRAS e de Português na modalidade escrita para os surdos, e com o ensino de LIBRAS e Português como L1 para ouvintes. Para isso, conta com uma equipe interdisciplinar - com assistente social, fonoaudióloga, pedagoga, psicóloga, professores de LIBRAS e instrutores surdos -, pois desenvolve, paralelamente ao ensino regular, um atendimento específico para os alunos surdos, que busca atender às especificidades educacionais desse público.

Na segunda visita à escola, foi feita uma entrevista com uma das coordenadoras. Foram elaboradas previamente algumas perguntas - guiadas a partir de pontos de interesse (GIL, 2007) - e outras considerações foram feitas a partir das questões que emergiram da fala da entrevistada.

Ao ser perguntada sobre o contexto de uma escola onde há surdos e ouvintes, a coordenadora explicou que a relação entre os grupos é aparentemente natural e os 
conflitos, muitas vezes, não ocorrem por causa da diferença linguística, e sim por outras questões relacionadas à idade, como o tipo físico ou a aparência. Outros fatores também emergem nesse contexto, como a influência da família ou questões de preferência do próprio indivíduo em se relacionar apenas com surdos ou apenas com ouvintes.

Em relação à aprendizagem, a coordenadora comenta que, em geral, os alunos surdos e os ouvintes demonstram vontade de aprender LIBRAS. No entanto, os perfis dos surdos são muito heterogêneos. Isso porque, apesar de a situação mais vista ser a chegada de uma criança surda que não sabe o Português oral nem a LIBRAS, há também surdos que chegam à escola já com o implante coclear; há crianças que são bem oralizadas; há crianças que não são oralizadas - e, segundo a coordenadora, demonstram facilidade em aprender a Língua de Sinais; há crianças que sentem dificuldade em fazer a leitura labial; entre diversos outros perfis. Logo, o que vai definir o trabalho com a criança surda são as próprias características apresentadas por ela, já que cada aluno apresenta histórias de vida diferentes, diferentes criações por parte dos pais e ideologias de vida diferentes. A coordenadora também critica os programas que enxergam esse processo de ensinoaprendizagem do surdo como um programa fechado que soluciona todas as dificuldades apresentadas por todos os surdos, como se eles fossem iguais.

Em relação à família, esta também apresenta um perfil diversificado. Segundo a coordenadora, os pais trazem, muitas vezes, a crença de que eles não fazem parte do processo de aprendizagem do filho surdo e que é papel da escola resolver todas as dificuldades apresentadas pelo aluno, fato que acaba dificultando o desenvolvimento da criança. Um exemplo é a questão da aprendizagem de LIBRAS: segundo a coordenadora, apesar de as mães terem o desejo de que os filhos saibam a língua de sinais, a maioria não sabe e não demonstra interesse em aprender, mesmo a escola oferecendo cursos gratuitos dessa língua. Isso acaba dificultando o processo de aprendizagem do aluno surdo, pois, como os pais não falam LIBRAS, muitas vezes, ele tem contato com a língua de sinais apenas na escola.

O perfil das mães construído pela coordenadora contrasta com as mães descritas por Batista (2006), que realiza uma pesquisa sobre as identidades discursivas nas narrativas de mães ouvintes de crianças surdas. Segundo a autora, mesmo apresentando interesse pela LIBRAS e tentando aprendê-la, as mães sentem dificuldade em falar com seus filhos e expressar conceitos ou ideias abstratas nessa língua. Isso nos mostra que 
talvez haja outras variáveis contextuais, como educação e nível socioeconômico, que influenciam o interesse das mães pela LIBRAS.

A respeito das categorias de análise, a ausência de língua foi a primeira categoria que emergiu dos dados gerados na entrevista. Levando em conta a falta de diálogo entre as áreas da Saúde e da Educação, geralmente, os pais não recebem informação alguma sobre a LIBRAS e sua importância quando descobrem que o filho é surdo. Isso faz com que a criança surda chegue à escola sem saber a LIBRAS nem língua alguma. Isso nos mostrou que as práticas, além de focarem o ensino de Português como segunda língua, deveriam também propiciar reflexões sobre a LIBRAS, de modo que o aluno surdo também aprenda mais sobre essa língua e sua importância para o desenvolvimento cognitivo, afetivo e os processos de socialização (SALIÉS, 2011).

A outra categoria que emergiu foi o papel da família no processo de aprendizagem do aluno surdo. Como, muitas vezes, os pais da criança surda não sabem LIBRAS, a comunicação entre a família fica truncada, reduzindo-se a gestos caseiros e mímicas. Além da questão cognitiva, isso faz com que a criança surda chegue à escola sem o conhecimento de mundo prévio tão rico quanto o do ouvinte, já que são os pais que geralmente explicam ensinamentos e aspectos culturais da sociedade para a criança. Tendo em conta que os indivíduos incorporam valores e ideologias por meio da vivência das rotinas sociais mediados pela linguagem - assim como aponta Giddens (1990) -, essa problemática sinalizou que as práticas precisavam também trabalhar com aspectos culturais, tanto da comunidade surda quanto da ouvinte, para que o aluno surdo saiba mais sobre a LIBRAS e sobre o Português.

Por fim, destaca-se a heterogeneidade, categoria que permitiu delinear aproximadamente um público-alvo para os materiais apresentados na presente proposta. Como apontou a coordenadora entrevistada, há surdos que sabem LIBRAS, outros que foram oralizados, outros que sabem as duas línguas, outros que querem apenas aprender o Português como L1, outros que só querem aprender LIBRAS, entre outros aspectos. Isso mostra que, ao pensarmos nas necessidades dos alunos surdos e sua relação com a LIBRAS e o Português, devemos evitar generalizações, para que não ocorram apagamentos de identidade ou sejam criados estereótipos em relação à comunidade surda.

Levando em conta o perfil heterogêneo dos alunos surdos, foi necessário delimitar o público-alvo do material a ser elaborado. Para isso, foram utilizados os descritores 
ACTFL Performance Descriptors for Language Learners $2012^{3}$, documento que descreve o desempenho do aprendiz ao tentar se expressar na L2, ou seja, o que os estudantes precisam saber e o que são capazes de produzir em termos de discurso em uma L2.

Como apenas duas habilidades são trabalhadas na proposta - leitura e escrita -, os descritores foram adaptados para tal contexto. As práticas pedagógicas desenvolvidas são voltadas para alunos surdos que saibam LIBRAS e que, no processo de aprendizagem da Língua Portuguesa na modalidade escrita, podem se expressar em conversas sobre tópicos familiares usando sentenças simples; compreendem o sentido de uma ideia simples a partir de suporte visual e palavras e frases que já internalizaram e que são capazes de recuperar da memória; e conseguem expressar informações sobre tópicos familiares, ligados à sua realidade psicológica. A tabela a seguir descreve os descritores adaptados:

Tabela 1: Descritores do público-alvo adaptados

\begin{tabular}{l}
\hline * O aprendiz se expressa em conversas sobre tópicos familiares usando sentenças simples; \\
\hline * Ele compreende o sentido de uma ideia simples a partir de suporte visual e palavras e frases que já \\
internalizou e que é capaz de recuperar da memória; \\
\hline$*$ Ele consegue expressar informações sobre tópicos familiares, ligados à sua realidade psicológica. \\
\hline
\end{tabular}

A partir das visitas à escola Integração e da entrevista com a coordenadora da escola, foi possível perceber como a área de Português para surdos é um contexto complexo. A escola em questão defende a Comunicação $\operatorname{Total}^{4}$ e, segundo a coordenadora, o encaminhamento para alunos surdos pode ser a oralização e a língua de sinais, dependendo das particularidades apresentadas por eles. É importante destacar que tal ponto de vista diverge da perspectiva da presente investigação, que defende o ensino da LIBRAS como L1 do surdo e do Português como segunda língua na modalidade escrita, sendo a oralização uma escolha da família e do próprio sujeito surdo. No entanto, ressalta-se também que não há fórmulas prontas para tal ensino, devido ao fato de a área ser muito heterogênea - como explica a própria coordenadora, cada surdo apresenta um perfil diverso, já que cada um terá uma relação diferente com a Língua Portuguesa e com a LIBRAS. Essas ideias conversam com a condição Pós-Método, proposta por Kumaravadivelu (1994), que aponta a necessidade de olharmos para as variáveis do contexto de ensino-aprendizagem com flexibilidade. 
Dessa forma, o estudo em questão busca não generalizar dados ou apresentá-los como uma verdade absoluta, e sim refletir sobre a área, dialogando com a visão de ensino e aprendizagem de línguas que vai ao encontro da Teoria dos Sistemas Complexos e que defende a LIBRAS como primeira língua e o ensino de Português como segunda língua na modalidade escrita.

\section{A PESQUISA BIBLIOGRÁFICA: DEFININDO CRITÉRIOS PARA AS PRÁTICAS PEDAgógICAS}

Para responder a questão (b) Quais critérios devem ser utilizados para a elaboração de práticas pedagógicas no ensino de Português como L2 para surdos?, foi realizada uma pesquisa bibliográfica de autores nas áreas de Aquisição de Segunda Língua, Teoria dos Sistemas Complexos, Condição Pós-Método, Ensino de Português para Surdos e Materiais para o ensino de PL2.

No quesito da Aquisição de Segunda Língua, foi levado em conta o fato de que, como aprender uma língua é também aprender sobre uma segunda cultura, o processo de aquisição relaciona-se com a reconstrução de identidade do aprendiz (PEIRCE, 1995). Nesse contexto, foram trabalhados nas práticas pedagógicas aspectos culturais da comunidade surda e da comunidade ouvinte, para que fossem incentivadas discussões e reflexões sobre ambas. Outra variável envolvida no processo de aquisição é a motivação, que, por sua vez, envolve a afetividade e as ações que influenciam o grau de esforço que os aprendizes depreendem para aprender uma segunda língua. Por isso, foram utilizados textos que fizessem parte da realidade do aluno surdo e abordassem questões sobre sua cultura, como a LIBRAS e a percepção visual.

Como a aprendizagem de nenhuma língua ocorre sem input, os aprendizes devem ser expostos a situações comunicativas para que haja contato com modelos de uso da segunda língua e para que seja adquirida experiência linguística. Com isso, buscou-se incentivar nos materiais oportunidades de prática da língua em situações comunicativas em pares, propiciando também o output do aprendiz. Trabalhar com o output mostra-se importante durante o processo de aprendizagem porque ajuda o aprendiz a: testar suas hipóteses; perceber os saltos em sua interlíngua ${ }^{5}$; avaliar as lacunas presentes entre a sua L1 e a língua-alvo; notar as possibilidades de formas que podem ser produzidas utilizando 
seu conhecimento gramatical, e aumentar sua conscientização sobre o processo de aquisição.

Destaca-se também o papel da instrução na aprendizagem de segunda língua. Estudos mostram que a instrução com foco na forma pode facilitar o processo de aquisição, pois ajuda o aprendiz a perceber o funcionamento da língua (TERRELL, 1982; ELLIS, 1997). Logo, buscou-se promover nas práticas a reflexão sobre a língua-alvo, contemplando o papel da L1 como estratégia cognitiva e afetiva e ajudando os aprendizes a criarem suas hipóteses sobre a L2.

No âmbito da condição Pós-Método (KUMARAVADIVELU, 1994), foram integradas as seguintes macroestratégias nas atividades: (1) maximizar as oportunidades de aprendizagem; (2) facilitar a interação negociada; (3) minimizar mal entendidos de percepção; (4) ativar heurística intuitiva; (5) promover a conscientização sobre a linguagem; (6) contextualizar o input linguístico; (7) integrar as competências linguísticas; (8) promover a autonomia do aluno; (9) aumentar a consciência cultural, e (10) assegurar a relevância social.

Entre os aspectos discutidos sobre a Teoria dos Sistemas Complexos, a proposta teve como objetivo propiciar a autonomia, atratores discursivos, agência e construção da identidade dos aprendizes, além de contemplar os contextos autênticos de produção e pontos de bifurcação. Isso porque tal teoria esclarece que, quanto maior for o contato do aprendiz com situações de uso da língua, maior é a possibilidade de ele se tornar proficiente na mesma, pois terá a oportunidade de participar de diversas comunidades de prática e reutilizar os recursos de uma comunidade em outra. A partir desse contato, o sistema tende a passar por diversos pontos de bifurcação, já que o aprendiz potencialmente enfrentará momentos de risco e de decisão. Isso poderá desenvolver sua autonomia. Além disso, como explica o conceito de agência, o aprendiz terá oportunidades de atuar socioculturalmente, já que usar uma segunda língua é também agir no mundo. Por fim, a presença dos atratores discursivos permite que o aprendiz conheça a cultura da língua-alvo e, dessa forma, reconstrua sua identidade a partir da emergência de outras novas identidades.

Já em relação aos critérios que emergiram da revisão de literatura sobre Português para surdos, destacaram-se os aspectos culturais, a LIBRAS e o ensino da Língua Portuguesa como segunda língua na modalidade escrita. O contato com processos 
culturais e produtos elaborados pela comunidade surda pode aproximar o aluno do material em questão, já que, para aprender o Português como segunda língua, é necessário também que o surdo se identifique e se motive com o contexto de aprendizagem. Levando em conta que a LIBRAS tem uma estrutura diferente da Língua Portuguesa, foi necessário também que reflexões sobre essas diferenças fossem problematizadas nas práticas pedagógicas, de modo que isso ajudasse o aluno surdo a elaborar hipóteses sobre a línguaalvo e a canalizar os mecanismos de atenção para a forma e para respectivas projeções de forma sobre função.

Além disso, pensar sobre as especificidades da escrita da Língua Portuguesa é de grande relevância no processo de aprendizagem dessa modalidade. Para que isso ocorra, é fundamental a reflexão sobre os aspectos lexicais, gramaticais e funcionais dos textos. A literatura (FERNANDES, 2006; LEBEDEFF, 2010) revela ser importante que as práticas pedagógicas voltadas para surdos também sejam pautadas na experiência visual e no trabalho com os mais variados gêneros textuais que circulam na sociedade. Nesse contexto, a proposta propõe o trabalho com gêneros que fazem parte do cotidiano do público-alvo, como contos de fadas, histórias em quadrinhos, entre outros.

Com isso, a escolha do tipo textual narrativo justifica-se, pois, além de ser um tipo textual presente no gênero conto de fadas, é uma das primeiras práticas sociais mediadas pela linguagem com a qual a criança tem contato. Por ser também temporal, causal, episódico e transacional, ele exige do aprendiz a transformação de conhecimento de um estágio posterior e o estabelecimento de relações causais e temporais entre eles (SALIÉS, 2011). Segundo Brockmeier e Carbaugh (2001), a narrativa é um meio de se comunicar, de expressar as experiências e compreender o mundo e a nós mesmos. Nesse sentido, alguns estudos atuais abordam o papel das narrativas na ordenação de experiências e no uso da memória, por exemplo.

Tomlinson (1999) explica que as práticas pedagógicas devem ser baseadas em princípios, como dialogar com o currículo, trabalhar com textos, propiciar a interação e incentivar o aprendiz a focar em aspectos formais da língua, a desenvolver habilidades para a aprendizagem e a utilizar essas habilidades durante o processo de aprendizagem da segunda língua. Tendo em conta a ideia de escrita como um processo e uma descoberta daquilo que se sabe e daquilo que não se sabe, foi importante também que as práticas pedagógicas considerassem os momentos apontados por White \& Arndt (1991): (1) 
criação e organização de ideias; (2) foco e escolha das principais ideias; (3) estruturação do texto; (4) elaboração do rascunho; (5) avaliação do texto que foi elaborado, e (6) revisão do que foi escrito para elaborar a versão final do texto.

Em síntese, a figura I conjuga os critérios em que as práticas pedagógicas foram baseadas, definidos a partir da revisão de literatura:

Figura 1: Critérios para a elaboração das práticas pedagógicas

\section{Critérios para a elaboração de materiais de PL2 para surdos}

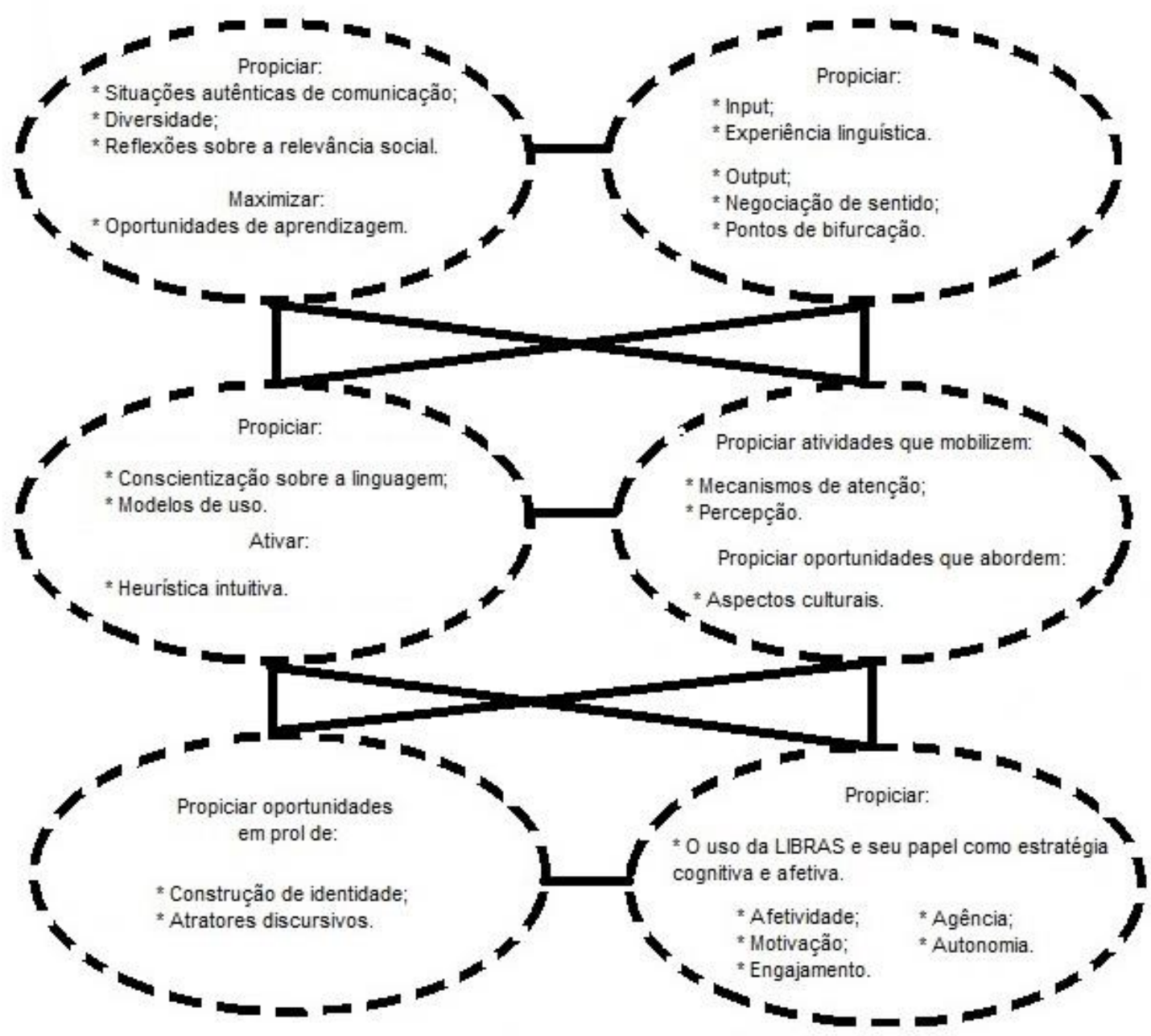




\section{AS PRÁTICAS PEDAgógICAS}

Voltadas para alunos surdos do $6^{\circ}$ ano do $2^{\circ}$ segmento do ensino fundamental, as atividades elaboradas podem ser trabalhadas ao longo de várias aulas durante o ano letivo. O ponto de partida são gêneros como o conto de fadas e a história em quadrinhos. Já os conteúdos trabalhados na unidade - verbos no passado - foram escolhidos porque emergiram a partir do trabalho com os gêneros citados.

Seguindo as sugestões de Saliés (2011), as práticas organizam-se em: préatividades, atividades e pós-atividades. O objetivo geral do material é propiciar oportunidades de narração de histórias e os objetivos específicos são propiciar oportunidades de aprendizagem de verbos no passado. A seguir, são apresentadas algumas propostas de práticas pedagógicas.

PRÉ-ATIVIDADES: têm como objetivo introduzir o tema que será trabalhado e construir o conhecimento prévio, inserindo o aprendiz em práticas sociais e fazendo com que ele vivencie situações de uso.

$1^{\text {a }}$ pré-atividade - Trabalhar o conto "O Patinho Feio". Após ser exibido o vídeo que narra a história, pedir que o aluno conte, em LIBRAS, o que foi visto e escreva, em Português, quais as ideias principais.

Figura 2: $1^{\text {a }}$ pré-atividade

Vamos conhecer mais sobre a história Patinho Feio? Veja o vídeo abaixo:

Disponível em: https://www.youtube.com/watch?v=sBBulj3HotM

- Após ver o vídeo acima, conte para a turma, em LIBRAS, o que você entendeu da história.

- Depois, faça um resumo em Português contando a história. O resumo pode ser feito com frases soltas que mostrem as ideias principais ou desenhos que representem os momentos mais importantes.

$2^{\text {a }}$ pré-atividade - Apresentar imagens das capas de livros infantis adaptados que tratam de aspectos da cultura surda e propor um debate em LIBRAS. 
Como aprender uma segunda língua é também aprender uma segunda cultura, as práticas devem trabalhar também com o aumento da conscientização cultural do aprendiz, pois, ao ter contato com atratores discursivos, ele pode refletir sobre os costumes e modos de pensar da sua L1 e da língua-alvo.

Figura 3: $2^{\mathrm{a}}$ pré-atividade

- Você sabia que, além de traduções de histórias do Português para LIBRAS, há também adaptações que falam sobre a comunidade surda? Pesquise na internet alguns exemplos.

- Você conhece os contos que lembram o Patinho surdo, a Cinderela surda e a Rapunzel surda? Quais são suas histórias?

- Na sua opinião, quais possíveis semelhanças e diferenças há entre essas histórias e suas adaptações?

$3^{\text {a }}$ pré-atividade - Apresentar a história adaptada do conto "O Patinho Feio", que fala sobre o Patinho Surdo. Depois de ser trabalhada essa história, pedir que o aluno a narre em LIBRAS.

O objetivo dessa atividade é propiciar que o aluno compare as duas versões da história e elabore hipóteses sobre o Português, pois, ao contar a história em LIBRAS, ele tem a oportunidade de refletir sobre as diferenças entre as duas línguas.

Figura 4: $3^{\mathrm{a}}$ pré-atividade

Vamos conhecer agora a história O Patinho Surdo? Leia o texto abaixo, que fala sobre essa versão adaptada do conto tradicional O Patinho Feio e converse com os seus colegas sobre as perguntas que se seguem:

\section{O Patinho Surdo}

Em uma lagoa tranquila, num dia ensolarado, no Rio Grande do Sul, chegou uma revoada de aves. De um lado ficaram os cisnes e de outro ficaram os patos surdos. Estavam todos na lagoa até que uma pata e um pato surdos se encontraram e começaram a sinalizar. Conversaram, conversaram até que começaram a namorar.

Os dois começaram a preparar um ninho, pois a pata iria colocar ovos. Ela pôs um ovo, depois outro, depois outro. Um dia em que ela precisava relaxar um pouco, saiu a nadar. E, passeando tranquila pelo lugar onde ficavam os cisnes, começou a sentir uma dor. E faltava colocar um ovo! Como não daria para voltar para o ninho, teria que ser ali mesmo. Viu um ninho dos cisnes, colocou o ovo ali. E foi embora triste, pois ali não era o seu ninho.

A mamãe cisne retornou e sentou no seu ninho. Dali alguns dias, ela sentiu algo se mexendo lá embaixo. Saltou logo para ver. Eram os ovos que começaram a quebrar. Os filhotes iam saindo e grasnando. A mamãe chamou logo o papai para ver os filhotes que iam nascendo e, de repente, sai um filhote sinalizando! O papai e a mamãe se olharam e acharam aquilo estranho, pois todos grasnavam e um sinalizava. 
Sem saber como aquilo acontecera, papai cisne saiu irritado. Mamãe não soube como reagir e como tratar o filhote diferente. Todos os cisnezinhos conversavam e o patinho ficava ali calado. Mamãe cisne levou todos para passear e eles cantavam, todos alegres. O patinho surdo começou a perceber que ali não era seu lugar.

- Todos conversavam e cantam e eu sinalizo.

Deixou o grupo e saiu nadando. Foi nadando angustiado, nadando, nadando. Passou por entre os juncos do lago e viu algo ao longe. Aproximou-se mais e viu outro grupo de cisnes sinalizando. Nadou, nadou... encontrou cisnes de outra família, negros e pescoço longo. Ele se aproximou. Os cisnes respondiam com sinais ao mesmo tempo em que oralizavam. Não, ali também não era o seu lugar.

Saiu nadando triste e solitário. Até que um grupo de irmãos sinalizava por ali e avistou o patinho, sozinho. O grupo de patinhos resolveu ir até lá. Aproximaram-se e chamaram o patinho. O patinho ficou aliviado, pois os outros patos também sinalizavam. Nisso, a mamãe pato o avistou e saiu correndo para abraçá-lo. Era seu filho que havia nascido em outro ninho!

Os cisnes já estavam desesperados procurando o patinho perdido. Quando, de repente, os cisnes e os patos se encontram! Não conseguiam se comunicar, pois os cisnes falavam e os patos sinalizavam. Tiveram a ideia de chamar o sapo, pois este era intérprete e poderia mediar a situação. O cisne perguntou pelo filho que estava perdido, então a mamãe pato explicou o que acontecera. Falou que um dia estava passeando quando precisou colocar um ovo, e o fez no ninho dos cisnes.

Então tudo ficou esclarecido. Com a ajuda do sapo intérprete, eles foram se comunicando e tudo ficou claro. Todos ficaram tranquilos. Felizes e unidos!

Disponível em: http://www.literaturasurda.com.br/musicvideo.php?vid=5cc2baaa1

- Conte, em LIBRAS, o que você entendeu sobre o texto acima.

- Após ler o texto acima, reflita: quais comparações podemos fazer entre as histórias O Patinho Feio e O

Patinho Surdo? Aponte as semelhanças e as diferenças que você notou.

$4^{\mathrm{a}}$ pré-atividade - Propor um debate sobre preconceito, tema presente nas duas histórias.

Essa é uma atividade de reflexão. Levando em conta a importância de abordar temas de relevância social na sala de aula, tal atividade busca propiciar oportunidades para que os alunos reflitam sobre o preconceito sofrido pelo Patinho feio e o Patinho surdo. 
Encontros e desencontros: uma proposta de práticas pedagógicas para o ensino de Português como L2

Figura 5: $4^{\mathrm{a}}$ pré-atividade

- As histórias O Patinho Feio e O Patinho Surdo falam sobre preconceito. Qual tipo de preconceito sofrido pelas personagens nas histórias? Na sua opinião, o que poderia ser feito para acabar com o preconceito?

- Discuta com seus colegas, em LIBRAS, quais os tipos de preconceito existentes e o que pode ser feito para acabarmos com eles. Elaborem um quadro para organizar as ideias:

\begin{tabular}{|c|c|}
\hline $\begin{array}{c}\text { O Patinho não deve } \\
\text { sofrer preconceito } \\
\text { porque é... }\end{array}$ & $\begin{array}{c}\text { O que podemos } \\
\text { fazer para acabar } \\
\text { com isso: }\end{array}$ \\
\hline$*$ feio; & \\
\hline$*$ surdo; & \\
\hline
\end{tabular}

- Agora é a sua vez! Em grupos, crie uma história em que a personagem principal sofre algum tipo de preconceito. Não se esqueça de propor na história uma solução para acabar com o preconceito sofrido. - Depois, apresente, em LIBRAS, a história criada para o resto da turma.

$5^{\text {a }}$ pré-atividade - Propor uma pesquisa para ser feita em casa sobre outras adaptações de histórias infantis que abordem aspectos culturais da comunidade surda.

Esta atividade tem como objetivo trabalhar com outras adaptações de contos infantis voltadas para a comunidade surda. Além disso, busca propiciar a autonomia e o engajamento do aprendiz para que ele conheça mais sobre sua cultura.

Figura 6: $5^{\mathrm{a}}$ pré-atividade

\section{Para casa...}

Você conhece outras adaptações de histórias infantis, voltadas para a comunidade surda? Escolha uma delas e pesquise na internet sobre sua história. Depois, responda: quais semelhanças e diferenças podemos destacar entre esses livros e os contos originais?

$6^{\text {a }}$ pré-atividade - Pedir para os alunos apresentarem, em LIBRAS, o trabalho de casa proposto anteriormente.

ATIVIDADES: têm como objetivo trabalhar a combinação entre o input compreensível e o foco na forma por meio da reflexão sobre o tema que está sendo trabalhado - no caso, elementos da narrativa. 
$1^{\text {a }}$ atividade - Trabalhar a história da Cinderela. Após ser exibido o vídeo que narra a história, pedir que o aluno conte, em LIBRAS, o que foi visto e escreva, em Português, quais as ideias principais.

Figura 7: $1^{\text {a }}$ atividade

Veja agora o vídeo Cinderela em LIBRAS:

Disponível em: https://www.youtube.com/watch?v=aw2ts6GfuLI

- Após ver o vídeo acima, conte para a turma, em LIBRAS, o que você entendeu da história.

- Depois, faça um resumo em Português contando a história. Novamente, o resumo pode ser feito com frases soltas que mostrem as ideias principais ou desenhos que representem os momentos mais importantes.

$2^{a}$ atividade - Ler o texto da história infantil "Cinderela" e responder as perguntas em LIBRAS.

Neste momento do encontro, o foco na forma é voltado para a ideia de passado nos verbos.

Figura 8: $2^{\mathrm{a}}$ atividade

Você conhecia a história Cinderela? Leia o texto abaixo e faça o que se pede:

\section{Cinderela}

Era uma vez no tempo dos reis e rainhas, uma linda menina que se chamava Cinderela. Ela morava com uma madrasta muito má! A madrasta de Cinderela tinha duas filhas. Essas irmãs de Cinderela eram duas moças muito egoístas e que não gostavam de trabalhar e, por isso, era Cinderela que tinha de fazer tudo em casa.

Um dia Cinderela ajudou as irmãs a se vestirem para um grande baile. Mas sua madrasta impediu Cinderela de ir, pois tinha afazeres domésticos para terminar. Delegou tanta coisa à Cinderela que ela jamais terminaria em tempo de ir ao baile. Pobre Cinderela!

Seus amiguinhos, inconformados com a situação, se puseram a trabalhar para confeccionar um lindo vestido para que Cinderela pudesse ir ao baile também. Sim, o vestido estava pronto e Cinderela podia ir ao baile, como suas irmãs. Ela estava linda! Mas, Cinderela não conseguiu terminar o seu serviço, portanto não iria ao baile tão esperado!

De repente, do azul aparece sua madrinha para ajudá-la. A madrinha de Cinderela agitou a varinha de condão. Olhou para Cinderela, escolheu o vestido mais bonito e com sua varinha mágica, transformou-a numa princesa! Uma abóbora que havia na cozinha logo se transformou numa bela carruagem. Seus amiguinhos, a fada madrinha os transformou em cocheiro e mordomo. Todos queriam colaborar e levar Cinderela ao baile. A roupa velha de Cinderela virou um vestido de cetim.

- Vá e se divirta - disse a velhinha.

- Mas trate de voltar para casa antes de bater meia-noite.

E Cinderela chega ao baile. Logo o príncipe se encanta e a tira para dançar. No palácio, a beleza e a simpatia de Cinderela conquistaram a todos. O príncipe dançou com ela muitas vezes. O tempo passou 
depressa e, para surpresa dela, o relógio do palácio começou a bater meia-noite. Cinderela logo se lembrou do aviso da madrinha.

Assustada, Cinderela fugiu correndo, mas deixou cair um pequenino sapato de vidro. O príncipe pegou o sapato e decidiu que havia de casar com a sua dona, que havia conquistado o seu coração. Uma carta do reino chega à casa de Cinderela anunciando a chegada do príncipe. $\mathrm{O}$ príncipe procurou por todo o reino. Finalmente chegou à casa onde morava Cinderela.

As irmãs experimentaram calçar o sapato, mas seus pés eram grandes demais. Até que chegou a vez de Cinderela, depois de muito custo, pois a madrasta havia trancado a pobre moça. Mas com a ajuda de seus amiguinhos, ela consegue chegar a tempo de poder provar o sapatinho. $\mathrm{O}$ sapato deu certinho no pé de Cinderela. Vibrando de alegria, o príncipe pediu Cinderela em casamento. O rei estava feliz porque seu filho havia encontrado uma linda moça que se tornaria a mais linda princesa de seu reino. Portanto, viveram felizes para sempre.

Disponível em: http://www.contandohistoria.com/cinderela.htm

- Como Cinderela era tratada pela madrasta e pelas irmãs?

- Cinderela fica triste quando a sua madrasta a proíbe de ir ao baile. No entanto, ela recebe uma visita que muda seu destino. Quem é a pessoa que vai à casa dela?

- O que essa pessoa fez para ajudar Cinderela?

- A Cinderela esquece no baile:

$\begin{array}{ll}(\quad) \text { a bolsa } & (\quad) \text { o sapato }(\quad) \text { um anel } \\ (\quad) \text { a carteira } & (\quad) \text { o celular }(\quad) \text { a chave de casa }\end{array}$

- O que o príncipe fez para encontrar Cinderela?

- O que a madrasta de Cinderela fez para impedir que a moça experimentasse o sapatinho de cristal?

- Observe as palavras sublinhadas no texto. Elas descrevem ações que já aconteceram, que estão acontecendo ou que ainda vão acontecer?

\section{$3^{\mathrm{a}}$ atividade - Trabalhar com verbos no passado.}

É o momento do encontro em que conceitos são introduzidos a partir das respostas dadas na atividade anterior.

Figura 9: $3^{\mathrm{a}}$ atividade

$$
\text { Sistematizando ideias... }
$$

Quando contamos uma história, narramos fatos que já aconteceram. Por isso, geralmente utilizamos verbos no passado. Observe as frases abaixo, retiradas da história da Cinderela:

Cinderela morava com uma madrasta muito má! (verbo morar)

As irmãs de Cinderela não gostavam de trabalhar. (verbo gostar)

A madrinha de Cinderela agitou a varinha de condão. Olhou para Cinderela, escolheu o vestido mais bonito e com sua varinha mágica, transformou-a numa princesa! (verbo agitar / olhar / escolher / transformar)

Repare que os verbos "morava" e "gostavam" indicam hábitos que aconteciam no passado e, por isso, estão no tempo verbal PRETÉRITO IMPERFEITO DO INDICATIVO. Já os verbos "agitou”, “olhou”, "escolheu" e "transformou" indicam ações completas que ocorreram no passado. Logo, esses verbos estão no PRETÉRITO PERFEITO DO INDICATIVO. 
$4^{\mathrm{a}}$ atividade - Pedir que os alunos organizem os verbos do quadro de acordo com seus tempos verbais, separando os verbos que estão no Pretérito Perfeito do Indicativo dos que estão no Pretérito Imperfeito do Indicativo.

Figura 10: $4^{\mathrm{a}}$ atividade

\section{Para casa...}

No quadro abaixo, há alguns verbos presentes no texto Cinderela. Organize os verbos, separando os que estão no Pretérito Perfeito do Indicativo e os que estão no Pretérito Imperfeito do Indicativo:

\begin{tabular}{|c|c|}
\hline \multicolumn{2}{|c|}{$\begin{array}{c}\text { chamava - agitou - olhou - estava - pegou - procurou - conquistava - ajudava - lembrou - } \\
\text { deixou - delegava - transformou - passou - começou - chegou - dançava - experimentou }\end{array}$} \\
\hline VERBOS NO PRETÉRITO & VERBOS NO PRETÉRITO \\
PERFEITO & IMPERFEITO \\
\hline
\end{tabular}

$5^{\mathrm{a}}$ atividade - Corrigir o trabalho de casa proposto anteriormente.

Figura 11: $5^{\mathrm{a}}$ atividade

\begin{tabular}{|c|c|}
\hline \multicolumn{2}{|c|}{ Correção } \\
\hline $\begin{array}{c}\text { VERBOS NO } \\
\text { PRETÉRITO PERFEITO }\end{array}$ & $\begin{array}{c}\text { VERBOS NO } \\
\text { PRETÉRITO IMPERFEITO }\end{array}$ \\
\hline $\begin{array}{c}\text { agitou - olhou - pegou - procurou } \\
\text { lembrou - deixou - transformou passou - estava - conquistava } \\
\text { começou - chegou } \\
\text { experimentou }\end{array}$ & \begin{tabular}{c} 
ajudava - delegava -dançava \\
\hline
\end{tabular} \\
\hline
\end{tabular}

$6^{\mathrm{a}}$ atividade - Introduzir conceitos a partir das respostas dadas na atividade anterior.

Essa atividade tem como objetivo trabalhar com as terminações de verbos no Pretérito

Perfeito do Indicativo e Pretérito Imperfeito do Indicativo.

Figura 12: $6^{\text {a }}$ atividade

\begin{tabular}{|l|}
\hline Observe os verbos organizados na tabela anterior. Repare que os verbos de cada tabela terminam \\
com as mesmas letras. Isso porque, para indicarmos a ideia de tempo no Português, utilizamos \\
determinadas terminações. Essas terminações são chamadas de desinências. Para entendê-las melhor, \\
observe o texto abaixo: \\
Mais um conto de fadas que amamos ganhará uma versão moderna. O filme Cinderela estreia somente \\
em abril de 2015 , mas seu figurino já está pronto e tentaram modernizar as peças em comparação a
\end{tabular}


primeira versão cinematográfica, que criaram há mais de 50 anos atrás. Para começar, o sapatinho de cristal foi inspirado em um modelo de 1890, encontrado em um museu. Já o vestido que Cinderela usou no baile possui saia volumosa graças a mais de uma dúzia de camadas de seda, em diferentes tons de azul. Os outros figurinos de festa também prometem muita inspiração para a vida real. Eu amei o outro filme e mal posso esperar para ver esta nova versão. E que venha o príncipe encantado!

Texto adaptado de: $\underline{\text { http://yeswedding.uol.com.br/pt/antena-yes/post/cinderela-moderna }}$

Sistematizando ideias...

Os verbos "tentaram", “criaram", "usou", "amei" são os verbos "tentar", "criar", "usar" e "amar" no Pretérito Perfeito do Indicativo. Repare que todos esses verbos terminam com AR e, por isso, seguem a mesma regra de terminações no pretérito perfeito e no pretérito imperfeito:

\begin{tabular}{|c|c|c|c|c|}
\hline \multicolumn{5}{|c|}{ PRETÉRITO PERFEITO } \\
\hline eu & tentei & criei & usei & amei \\
\hline tu & tentaste & criaste & usaste & amaste \\
\hline ele/ela & tentou & criou & usou & amou \\
\hline nós & tentamos & criamos & usamos & amamos \\
\hline vós & tentastes & criastes & usastes & amastes \\
\hline eles/elas & tentaram & criaram & usaram & amaram \\
\hline \multicolumn{5}{|c|}{ PRETÉRITO IMPERFEITO } \\
\hline eu & tentava & criava & usava & amava \\
\hline tu & tentavas & criavas & us $\underline{a v a s}$ & amavas \\
\hline ele/ela & tentava & criava & usava & amava \\
\hline nós & tentávamos & criávamos & usávamos & amávamos \\
\hline vós & tentáveis & criáveis & usáveis & amáveis \\
\hline eles/elas & tentavam & criavam & usavam & amavam \\
\hline
\end{tabular}

$7^{\text {a }}$ atividade - Pedir que o aluno reflita sobre como o Português e a LIBRAS expressam a ideia de tempo.

Esta atividade busca propiciar reflexões do aprendiz acerca da língua alvo e da sua L1.

Figura 13: $7^{\mathrm{a}}$ atividade

Discuta com seus colegas:

- Levando em conta as ideias apresentadas no quadro anterior, podemos concluir que as terminações dos verbos em Português seguem algumas regras. Quais são essas regras?

- E em relação à LIBRAS? Como falamos sobre ações habituais no passado e como falamos sobre situações pontuais que ocorreram no passado? Que diferenças e semelhanças existem entre a LIBRAS e o Português em relação às formas de expressar ideias no passado?

PÓS-ATIVIDADES: têm como objetivo reforçar as associações construídas ao longo do processo pelo aprendiz e fazer com que o aluno reflita sobre o que ele aprendeu, descubra o que ele não aprendeu e avalie a importância do tema para a sua vida. Busca-se também propiciar oportunidades para comparações, síntese e elaborações que envolvam processos descendentes e habilidades cognitivas superiores. 
$1^{\text {a }}$ pós-atividade - Com base no que foi apresentado no exercício anterior, pedir que o aluno organize a história da Rapunzel.

Figura 14: $1^{\mathrm{a}}$ pós-atividade

Vamos brincar de quebra-cabeça? Organize a história da Rapunzel de acordo com a ordem dos acontecimentos.

"Rapunzel! Rapunzel! Joga as tuas louras tranças! Sem demora, sem demora, que eu vou subir agora!

- Essa voz! Que alegria! O príncipe me encontrou. Não disse? Naquele dia, ele viu. Já pode subir, joguei minhas tranças! Mas como ele sobe rápido! A bruxa, para subir, leva quase um dia inteiro!

- Já sei por que ele demorou, tinham muitos caminhos. Mas me encontrou!

- É verdade e o que importa é cumprir o que jurei. Deste castelo sem porta, logo te libertarei.

- Mas como a bruxa malvada presta atenção lá fora. Quando está desconfiada, vem aqui a toda hora.

- Não faz mal, amanhã cedo, depois do cantar do galo, eu volto. Não tenha medo. Iremos no meu cavalo."

"O príncipe realmente viu a moça na janela e estava tentando falar com ela:

- Em meu cavalo, eu procuro o dia inteiro a moça que vi na janela, naquela torre comprida, sem porta, sem escada, sem entrada nem saída, sem saída nem entrada. Agora estou me lembrando, é a torre da bruxa má! Assim, andou mais um dia, sempre no caminho certo. Até que viu a linda princesa na torre." 
"No outro dia, enquanto o galo cantava, o príncipe inocente chegou na torre:

- Rapunzel! Rapunzel! Joga as tuas louras tranças! Sem demora que eu vou subir agora!

- Ah! Estão bem amarradas, pode subir.

Então o príncipe tentou subir, mas caiu de pernas para o ar.

A bruxa rindo gritou:

- Pobre louco que queria me enganar.

E o príncipe gritou:

- Ó! Meu Deus, eu não vejo nada! Fiquei cego! Foi feitiço, foi essa bruxa malvada, que por vingança fez isso!

E sete dias andou, sem ter um destino certo. Até que a sorte o levou, para os lados do deserto. Foi quando escutou uma voz familiar, que o deixou radiante, só de ouvi-la cantar!"

"Era um dia muito lindo, o sol redondo no céu, parecia estar sorrindo, menos para Rapunzel. Os passarinhos cantavam, abelhas colhiam mel, estavam todos felizes, menos Rapunzel. Ela era a mais linda das moças da redondeza. Pele rosada e olhar meigo das crianças! Os cabelos formavam compridas tranças. Mas seu rosto era triste:

- Vivo triste, nessa torre, onde a bruxa me prendeu! Todo mundo vive alegre, todo mundo menos eu. Vivo triste nessa torre, onde a bruxa me trancou, esperando, esperando, por quem nunca mais voltou!"

"Vivo triste no deserto, onde a bruxa me deixou, sete dias, sete noites e ninguém me encontrou, vivo triste no deserto, mas não deixo de cantar! Pois o príncipe, por certo ao me ouvir vem me buscar!"

- Rapunzel, aonde é que você está?

- Estou aqui, na tua frente! Estás cego, não me vê mais? Foi a bruxa certamente!

De cansaço, desmaiando, o príncipe foi ao chão e debruçada chorando, Rapunzel pegou em sua mão. Suas lágrimas caíram sobre seus olhos fechados que logo se abriram, completamente curados!

- É um milagre, com certeza, do teu amor que é tão belo. Será a minha princesa, rainha do meu castelo.

Os dois foram embora dali, se casaram e tiveram filhos, vivendo felizes para sempre!"

“- É uma verdadeira escada feita com o cabelo da Rapunzel, que vai do chão à sacada, facilitando a subida. Pelas tranças, realmente, lá vai a bruxa magrela, muito vagarosamente subindo até a janela.

- Rapunzel, trouxe maçãs, leite pão e alguns docinhos. Virei todas as manhãs. Não dê nada aos passarinhos, eles andam espalhando por aí, o que não devem e estão me atrapalhando. Pra teus amigos, não servem. Jogue as tranças novamente, que eu agora vou descer. Sejas boa e paciente, eu volto ao amanhecer.

- Pronto, a bruxa já desceu. Vou esperá-la sumir. E agora, lá vou eu! Rapunzel vai querer fugir daquela torre!"

"Dizendo isto, desceu pelas tranças. E do chão soprou-lhe o beijo que deu na palma da própria mão. Mas Rapunzel estava certa, meia hora se passou e a velha bruxa esperta, desconfiada voltou.

- Estou sentindo algo estranho e diferente no ar. Vou te bater, se você tentar me enganar. Por que está rindo? Antes que eu vá embora, me conta logo o que aconteceu!

- É que demora tanto, sobe tão devagarzinho e o príncipe, no entanto, sobe rapidinho! - Que desastrada, contei tudo pra megera. Essa bruxa desalmada vai virar fera.

- Ah, então era isso, o príncipe da floresta! Que desaforo! Vou cortar suas tranças, vou cortálas com tesourão de jardim! Vou te deixar no deserto onde, o sol te queimará e o teu príncipe jamais te encontrará!" 
"Usando uma corda, a bruxa desceu da torre com Rapunzel. Aos empurrões, foi levando Rapunzel até deixá-la chorando, sem ninguém para ajudá-la.

- Voltarei à torre agora, subo e recolho as tranças e o castigo não demora, me pagam essas crianças.

- E Rapunzel, ah, que sorte! Assim que se acalmou, seu coração bateu forte. Teve uma ideia! - Passarinhos, amiguinhos! Onde estão pra me ajudar! Tenho fome, tenho sede, já não posso caminhar. Passarinhos, para onde devo ir, estou perdida no deserto, já não posso resistir.

- Estamos todos aqui! Bem perto existe um riacho, vamos te conduzir, juntinhos voando baixo para a sombra, te cobrir! - Que bom lugar, sorte a minha! Tem sombra, frutas, que amor! Aqui viverei sozinha, mas não morro de calor".

"-Vivo triste, nessa torre, onde a bruxa me prendeu! Todo mundo vive alegre, menos eu.

-A torre, ali, a janela, é Rapunzel certamente! Poderei falar com ela, encontrei finalmente!

Mas logo se escondeu, ao ver a bruxa malvada, que apareceu, falando desafinada:

- Rapunzel! Rapunzel! Joga suas louras tranças! Sem demora, que eu vou subir agora!"

Disponível em: http://www.contandohistoria.com/rapunzel.htm

\section{$2^{\text {a }}$ pós-atividade - Ler um trecho da história "A Rapunzel” e responder os questionamentos em LIBRAS.}

O objetivo desta atividade é revisar os verbos no Pretérito Perfeito e no Pretérito

Imperfeito do Indicativo, propiciando reflexões acerca da diferença de sentido dos dois tempos verbais.

Figura 15: $2^{\mathrm{a}}$ pós-atividade

Observe o trecho abaixo, retirado da história A Rapunzel e faça o que se pede:

Era um dia muito lindo, o sol redondo no céu, parecia estar sorrindo, menos para Rapunzel. Os passarinhos cantavam, abelhas colhiam mel, felizes todos estavam, todos, menos Rapunzel. Quem era? Não disse ainda? Esqueci-me com certeza! Rapunzel era a mais linda das moças da redondeza. Pele rosada, fresquinha, olhar meigo das crianças! A cabeleira lourinha formava compridas tranças. Mas era triste o seu rosto e seu cantar mais ainda. Pois revelava um desgosto, nessa canção muito linda:

- Vivo triste, nessa torre, onde a bruxa me prendeu! Todo mundo vive alegre, todo mundo menos eu, vivo triste nessa torre, onde a bruxa me trancou, esperando, esperando, por quem nunca mais voltou!

- Quais os verbos no texto acima estão no tempo verbal Pretérito Perfeito do Indicativo?

- E quais os verbos no texto acima estão no tempo verbal Pretérito Imperfeito do Indicativo?

- Retire do texto uma frase no Pretérito Perfeito do Indicativo e a reescreva no Pretérito Imperfeito do Indicativo.

- Retire do texto uma frase no Pretérito Imperfeito do Indicativo e a reescreva no Pretérito Perfeito do Indicativo.

- Observando as novas frases elaboradas nas perguntas anteriores, que mudanças de sentido podem ser percebidas quando escrevemos uma frase utilizando verbos no Pretérito Perfeito do Indicativo e quando a escrevemos utilizando o tempo verbal Pretérito Imperfeito do Indicativo? 
Encontros e desencontros: uma proposta de práticas pedagógicas para o ensino de Português como L2 para surdos

$3^{\text {a }}$ pós-atividade - Ler a história em quadrinhos e responder os questionamentos em LIBRAS.

Figura 16:3a pós-atividade

Leia o texto abaixo e responda as perguntas:
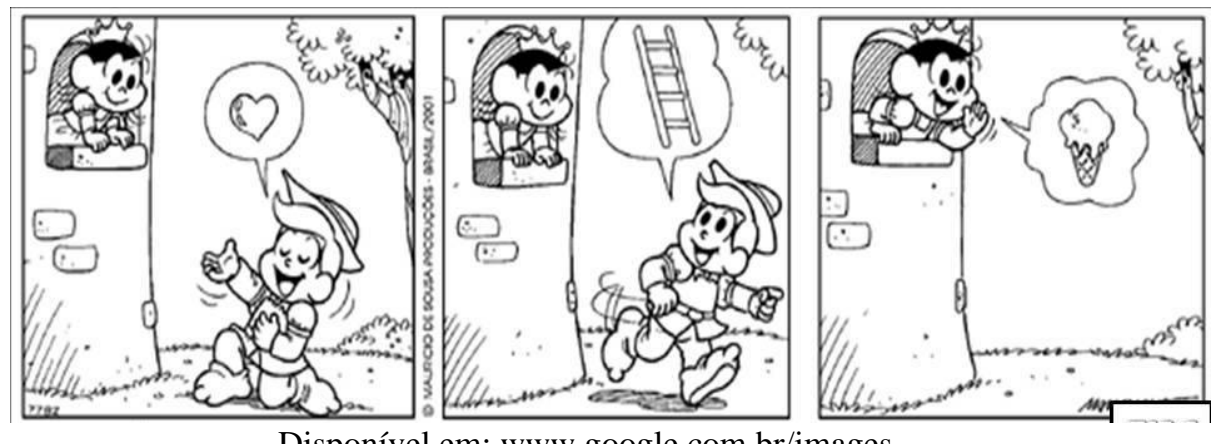

Disponível em: www.google.com.br/images

- Sobre o que fala a história? Explique para seus colegas, em LIBRAS.

- O que podemos interpretar da história a partir dos desenhos do coração, da escada e do sorvete, presentes dentro dos balões?

- A história em quadrinho acima se relaciona com a história Rapunzel. Indique uma semelhança e uma diferença entre os dois textos.

- Crie fala para os balões levando em conta as imagens:
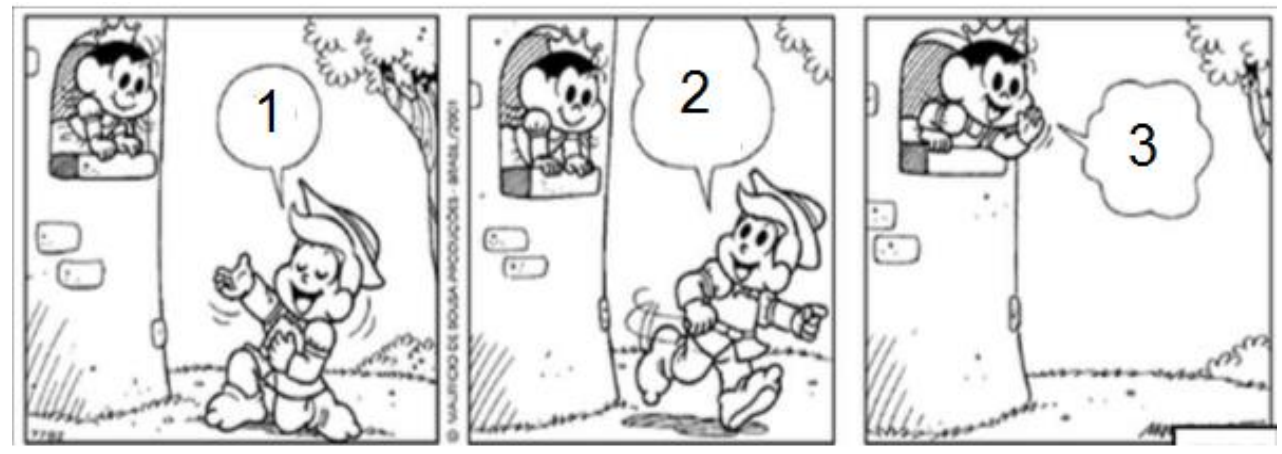

Para casa...

- Agora é a sua vez! Levando em conta sua resposta dada na pergunta anterior, elabore uma narrativa para a HQ. Não se esqueça de usar verbos aprendidos no passado!

$4^{\mathrm{a}}$ pós-atividade - Corrigir o trabalho de casa proposto anteriormente, pedindo que a turma apresente, em LIBRAS, a história feita.

\section{CONSIDERAÇÕES FINAIS}


O presente artigo teve como objetivo propor práticas pedagógicas para o ensino de Português como segunda língua para a comunidade surda. Para a definição dos critérios para a elaboração da proposta em questão, foi feita uma pesquisa bibliográfica nas áreas de Aquisição de Segunda Língua; Condição Pós-Método; Teoria dos Sistemas Complexos; Português para surdos e Materiais para o ensino de L2. Tal processo mostrouse um desafio por se tratar de um público tão heterogêneo. Além disso, a visita à escola Integração evidenciou como, muitas vezes, temos uma visão simplista e reducionista a respeito da comunidade surda ao acreditarmos que todos aprendem LIBRAS da mesma forma ou que todos têm a mesma relação com o Português.

Nesse contexto, propor a inclusão do surdo no ambiente escolar vai muito além da integração desse aluno no espaço físico da sala de aula: é necessário que sejam respeitadas suas especificidades e que seja disponibilizada estrutura adequada que atenda às suas necessidades. Propor a suposta inclusão sem pensar na presença de pares surdos, na aula ministrada em LIBRAS, na formação dos profissionais que trabalharão com esses alunos e em diversos outros fatores também mantém essa lógica excludente.

Além disso, tendo em conta que a perspectiva do presente artigo defende o desenvolvimento da comunidade surda por meio das línguas de sinais, é fundamental que os surdos tenham contato com a LIBRAS desde os primeiros anos de vida. Para que isso ocorra, os participantes envolvidos nesse processo precisam estar alinhados: o profissional de saúde que tem contato com a família quando ela descobre que o filho é surdo precisa ter consciência da importância da língua de sinais para o desenvolvimento cognitivo e afetivo daquela criança para que ele possa explicar para a família a necessidade do ensino da LIBRAS; os pais precisam também ter essa consciência e, além de propiciar o ensino da língua de sinais para o filho surdo, deveriam aprender LIBRAS para que a relação com seu filho não seja prejudicada devido à falta de uma língua em comum; os professores também deveriam aprender a LIBRAS e, principalmente, saber que o ensino do Português para a comunidade surda é o de uma segunda língua na modalidade escrita exclusivamente; a direção da escola também deveria ter o entendimento de que, para que o aluno surdo se desenvolva, é necessário o contato com pares surdos, aulas ministradas em LIBRAS, materiais adaptados, avaliações diferenciadas, funcionários que saibam LIBRAS, entre outros. Pensar na inclusão dos 
alunos surdos na sala de aula regular ultrapassa a adaptação de materiais: é necessária uma mudança social e cultural na nossa Educação atual.

Já em relação às práticas pedagógicas propostas, ressalta-se que a ordem e a seleção das atividades são flexíveis, podendo o(a) professor(a) adaptá-las ao seu contexto. Esse seria, inclusive, um possível desdobramento do presente estudo: aplicar as práticas aqui elaboradas em escolas que atendam ao público surdo, adaptando-as de acordo com o contexto. Outra possibilidade de extensão do trabalho é o desenvolvimento de pesquisas mais aprofundadas sobre as próprias especificidades dos alunos surdos oralizados, já que o panorama atual mostra a ausência de diálogos entre as áreas de pesquisa para surdos oralizados e sinalizantes. Logo, parece ser relevante pensarmos de que forma essas práticas pedagógicas aproximam-se ou se distanciam quando voltadas para ambos os públicos, já que surdos oralizados, por exemplo, podem não conhecer LIBRAS e nem se interessar por aspectos da cultura surda.

\section{Referências}

ACTFL. ACTFL Proficiency Guidelines. Yonkers, NY: ACTFL, 2012. Disponível em: http://actflproficiencyguidelines2012.org/

BATISTA, M. F. de S. Ser mãe ouvinte de filho surdo: a construção de identidade na narrativa de mães de crianças surdas. 2006. 188 folhas. Dissertação (Mestrado em Letras) - Instituto de Letras, Universidade do Estado do Rio de Janeiro, Rio de Janeiro.

BRASIL, MINISTÉRIO DA AÇÃO SOCIAL. Declaração de Salamanca e linha de ação sobre necessidades educativas especiais. Brasília: MAS/CORDE, 1994.

BROCKMEIER, J.; CARBAUGH, D. A. Narrative and identity: Studies in autobiography, self, and culture. Amsterdam: John Benjamins Pub, 2001.

ELLIS, R. Second Language acquisition. Oxford: Oxford University Press, 1997.

FERNANDES, S. Práticas de letramentos na educação bilíngue para surdos. Curitiba: SEED, 2006.

GIDDENS, A. The consequences of modernity. Cambridge: Polity Press, 1990.

GIL, A. C. Como elaborar projetos de pesquisa. $4^{\text {a }}$ ed. São Paulo: Atlas, 2007. 
KUMARAVADIVELU. B. The postmethod condition: (E)merging strategies for second/foreign language teaching. TESOL Quarterly, v. 28, n. 1, p. 27-48, 1994.

LACERDA, C. B. F. Um pouco da história das diferentes abordagens na educação dos surdos. In: Cadernos Cedes, vol. 19, nº 46. Campinas, 1998.

LEBEDEFF, T. B. Aprendendo a ler "com outros olhos": Relatos de oficinas de letramento visual com professores surdos. Cadernos de Educação, n. 36, p. 175-190, 2010.

LIGHTBOWN, P. M. Anniversary article: classroom SLA research and second language teaching. Applied Linguistics. v. 4, n. 21, p. 431-462, 2000.

PEIRCE, B. Social identity, investiment and language learning. TESOL Quarterly, v. 9, n. 1, p. 9-31, 1995.

SÁ, N. R. L. Educação de Surdos: a caminho do bilinguismo. Niterói: EduFF, 1999.

SALIÉS, T. M. G. Ensino-aprendizagem de PL2 na Comunidade Surda à luz de estudos em aquisição de L2. IX CBLA, 1, 2011, Rio de Janeiro. Linguística Aplicada e Sociedade. Rio de Janeiro: IX CBLA - ALAB, 2011, p. 1-19.

SELINKER, Larry. Interlanguage. International Review of Applied Linguistics, v.10, p.209-231, 1972.

TERRELL, T. D. The Natural Approach to language teaching: an update. In: Modern Language Journal, 1982, p. 121-132.

TOMLINSON, B. Developing criteria for evaluating L2 materials. IATEFL Issues, $\mathrm{n}$. 147, p. 10-13, 1999.

WHITE, R.; ARNDT, V. Process Writing. London: Longman, 1991.

Recebido em: 07/08/2021

Aceito em: 10/01/2022

\footnotetext{
1 Nome fictício da escola pesquisada.

${ }^{2}$ A escola Integração localiza-se no Rio de Janeiro.

${ }^{3}$ Inicialmente, os descritores são organizados a partir de três modelos de comunicação (interpessoal, interpretativo e apresentacional). O interpessoal diz respeito à ativa negociação de sentido entre os indivíduos; o interpretativo relaciona-se com a interpretação que o autor, falante ou produtor quer que o interlocutor da mensagem entenda; e o apresentacional refere-se à geração de mensagens. Todos dividemse em sete domínios: os três primeiros - função, contexto e tipo de texto - descrevem os parâmetros do desempenho dos aprendizes em cada faixa de desempenho (inicial, intermediário e avançado), e os outros quatro - controle da língua, vocabulário, estratégias de comunicação e conscientização cultural - descrevem como o aprendiz desempenha as funções em cada uma das faixas.
} 
${ }^{4}$ Como explica Sá (1999), Dorothy Shifflet, professora secundária e mãe de uma menina surda, começou a utilizar um método que combinava sinais, fala, leitura labial e treino auditivo, em uma escola na Califórnia, denominando seu trabalho de Total Approach - Abordagem Total. Assim, a Comunicação Total consistia no uso simultâneo de palavras e sinais, ou seja, no uso simultâneo de uma língua oral e de uma língua sinalizada. Segundo Lacerda (1998), estudos sobre práticas reunidas sob o nome de comunicação total têm apontado que, em relação ao oralismo, os surdos apresentam sérias dificuldades em expressar sentimentos e ideias e comunicar-se em contextos extra-escolares. Em relação à escrita, poucos sujeitos alcançam autonomia nesse modo de produção de linguagem. Em relação aos sinais, estes ocupam um lugar meramente acessório de auxiliar da fala, não havendo um espaço para seu desenvolvimento. Assim, muitas vezes, os surdos atendidos segundo essa orientação comunicam-se precariamente apesar do acesso aos sinais. É que esse acesso é ilusório no âmbito de tais práticas, pois os alunos não aprendem a compreender os sinais como uma verdadeira língua, e desse uso não decorre um efetivo desenvolvimento linguístico.

${ }^{5}$ De acordo com Selinker (1972), o desenvolvimento sistemático da língua do aprendiz reflete em um sistema mental do conhecimento da língua-alvo, conhecido como interlíngua. O aprendiz formula um sistema linguístico único e transitório, que é diferente da sua L1 e da língua alvo e que muda de acordo com o tempo, já que o aprendiz, a partir do uso de estratégias de aprendizagem, constrói, revisa e elimina regras antes elaboradas, reestruturando o sistema continuamente. Esse movimento resulta em um continuum, ou seja, os aprendizes constroem uma série de gramáticas mentais, a cada ponto do tempo. Lightbown (2000), ao problematizar a sistematicidade da interlíngua, fala sobre pesquisas que apoiam a ideia de que o aprendiz, durante o processo de aprendizagem de uma L2, comete erros sistemáticos iguais ao de uma criança na aprendizagem da L1. No entanto, apesar de haver a influência da L1 durante o processo de aquisição da L2, o conceito de interlíngua não pode ser entendido apenas como a mistura entre a L1 do aprendiz e a língua alvo, pois, se fosse o caso, haveria infinitos níveis de interlíngua, cada um com as características da L1 de cada aprendiz. Aprendizes com línguas maternas diferentes apresentam características semelhantes em sua produção da L2, como, por exemplo, as omissões, as supergeneralizações, etc. 